\title{
DETERMINATION OF PAMIDRONATE IN BISPHOSPHONATE-ENRICHED BONE CEMENT BY ION-PAIR HPLC AND CAPILLARY ELECTROPHORESIS
}

\author{
ŁUKASZ MATUSZEWSKI, ANNA MATUSZEWSKA ${ }^{1}$, TOMASZ MAZURKIEWICZ ${ }^{3}$, \\ IZABELA POLKOWSKA ${ }^{2}$, MAGDALENA JASZEK ${ }^{1}$, MARCIN GRĄZ ${ }^{1}$, AND JACEK GĄGAŁA ${ }^{3}$ \\ Paediatric Orthopedic and Rehabilitation Clinic, Medical University of Lublin, 20-093 Lublin, Poland \\ lukasz.matuszewski@am.lublin.pl \\ ${ }^{1}$ Biochemistry Department, Maria-Curie Sklodowska University of Lublin, 20-033 Lublin, Poland \\ ${ }^{2}$ Department and Clinic of Animal Surgery, Faculty of Veterinary Medicine, \\ University of Life Sciences in Lublin, 20-612 Lublin, Poland \\ ${ }^{3}$ Orthopaedic and Traumatology Department, Medical University of Lublin, 20-954 Lublin, Poland
}

Received: April 4, $2013 \quad$ Accepted: May 4, 2013

\begin{abstract}
The presence of pamidronate during local use of bisphosphonates (BP)-enriched bone cement was determined. The question was whether pamidronate implanted into the bone cement is eluted. The study was performed on 10 probes of BP-enriched bone cement located in $0.9 \% \mathrm{NaCl}$. The probes were incubated for 3 and 6 weeks. Ion-pair HPLC was used for the detection of pamidronate. Then, capillary electrophoresis was applied for quantitative analysis of pamidronate in the $3^{\text {rd }}$ and $6^{\text {th }}$ week after incubation. The presence of pamidronate, eluted from BP-enriched bone cement into $0.9 \% \mathrm{NaCl}$ solution 3 and 6 weeks after incubation, was demonstrated. These results may explain the changes in the level of cytokine RANKL and bone turnover marker osteoprotegrin in rats' serum treated with BP-enriched bone cement 3 and 6 weeks after surgery. The possibility of effective local use of BP-enriched bone cement in veterinary medicine was underlined. The results, and the former conducted research, point out that the clinical applications of BP-enriched bone cement in vivo may have some validity in the future.
\end{abstract}

Key words: rats, bisphosphonates, bone cement, ion-pair HPLC, capillary electrophoresis.

Bisphosphonates (BPs) are stable pyrophosphate analogs with the same basic structure, so called P-C-P group. Each BP has its own chemical, physicochemical, and biological characteristics (6). Recently an increasing number of reports have been published on the important effects of bisphosphonates on bone turnover. Therefore, BPs are widely used as inhibitors of bone resorption in the treatment of many skeletal disorders such as osteoporosis, malignant hypocalcaemia, bone metastasis, osteogenesis imperfecta or Paget's disease $(2,7,23,28,33)$. Despite the fact that BPs act specifically on osteoblasts and osteocytes, the complete mechanism of BPs' action is still unknown $(17,34)$. Pamidronate, with its specific binding affinities, appears to adsorb to calcium phosphate crystals in bone, thus blocking their dissolution by inhibiting osteoclast-mediated bone resorption. The main reason for a high efficacy of pamidronate is that it acts directly on bone tissue, therefore, the local use of pamidronate provides regulation of the secretion of various serum bone turnover markers, growth factors, or cytokines, such as osteprotegrin (OPG), receptor activator of NF- $\mathrm{kB}$ ligand (RANKL), and tumour necrosis factor (TNF- $\alpha$ ). In previous in vivo studies, where the BP-enriched bone cement was implanted into the tibia of rats, it was revealed that local use of pamidronate led to an increase in the quality of bone density, improved bones' microstructure, and might have had an influence on some bones' turnover markers $(20,21)$. Therefore, such findings might have an important effect on bone implant osteointegration in the prevention of bone collapse and also in the enhancement of implant fixation $(8,25)$. Many recent studies, both preclinical and clinical, also focused on further potential applications of BPs in orthopaedics $(4,8,9,13,36)$.

The present study aimed at assessing whether pamidronate implanted into the bone cement is eluted. Therefore, an attempt has been made to determine and assert the presence of pamidronate during local use of BP-enriched bone cement. It seems that BP-enriched bone cement might be very useful in treatment of trauma or bone defects in rats or other animals.

\section{Material and Methods}

Sample preparation. The study was performed on the probes of BP-enriched bone cement. Forty grams 
of the cement was mixed with $60 \mathrm{mg}$ of pamidronate. Rollers were formed with a diameter of $1 \mathrm{~cm}$ and a length of $2 \mathrm{~cm}$. Ten roller-shaped probes were prepared. The probes were incubated at $37^{\circ} \mathrm{C}$ in $25 \mathrm{~mL}$ Erlenmayer flasks containing $15 \mathrm{~mL}$ of $0.9 \% \mathrm{NaCl}$. Five probes were incubated for 3 weeks and the remaining five for 6 weeks. Ion-pair HPLC was used for detection of the eluted pamidronate. Then, capillary electrophoresis was used for quantitative analysis of eluted pamidronate under optimised conditions in the $3^{\text {rd }}$ and $6^{\text {th }}$ week after incubation. The time of incubation was congruous with our former experiments where effects of BP-enriched bone cement implanted into tibia bone in rats were assessed $(19,20)$.

Reagents. Pamidronate (3-amino-1hydroxypropylidene) bisphosphonate was obtained from Vipharm S.A. (Poland). Bone cement was purchased from CMW 1, DePuy International Ltd, England. Acetonitrile and methanol HPLC grade were purchased from Merck (Germany). N-butylamine and n-amyloamine were obtained from Sigma (USA) and tetrabutylammonium chloride and cetyltrimethylammonium bromide from Fluka (Switzerland). For mobile phase preparation MilliQ water was used.

Equipment. HPLC analysis was carried out using the reversed-phase column Phenomenex Luna C 18 column $(250 \mathrm{~mm} \times 4.6 \mathrm{~mm}$ I.D. $)$, particle size $5 \mu \mathrm{m}$, and was protected by a Phenomenex Security Guard column. The chromatographic system consisted of a LC-9A precision pump (Shimadzu, Japan), an SPDM10A diode array detector and a Model 7125 sampling valve RHEODYNE (USA) with $20 \mu \mathrm{L}$ loop, and was controlled by Shimadzu Class M10A Work Station (v.1.64). The mobile phase used was a mixture of $10 \mathrm{mM}$ n-amylamine at a constant $\mathrm{pH}$ of 7.0 and acetonitrile (14\%) (v/v). The flow-rate was $0.5 \mathrm{~mL} / \mathrm{min}$ and all experiments were done at room temperature. The spectra of tested substances were determined in a Shimadzu UV-VIS 160A spectro-photometer (Japan) controlled by Pentium IV PC computer with PC 160 plus software (19).

The capillary electrophoresis analysis was carried out using the thermo capillary electrophoresis, Crystal 100, (Thermo Separation Products, USA). Separation was carried out using a fused silica capillary with a total length of $75 \mathrm{~cm}(50 \mathrm{~cm}$ to detection window) and an inner diameter of $50 \mu \mathrm{m}$. Applied voltage was $-25 \mathrm{kV}$ and the capillary temperature was maintained at $25^{\circ} \mathrm{C}$. Samples were injected hydrodynamically for $0.5 \mathrm{~s}$ and the detection was performed at $210 \mathrm{~nm}$. Buffer solution ( $\mathrm{pH}$ 8.6) was prepared by dissolving $\mathrm{Na}_{2} \mathrm{HPO}_{4}(15 \mathrm{mmol} / \mathrm{L})$ and cetyltrimethylammonium bromide (CTAB, $0.6 \mathrm{mmol} / \mathrm{L}$ ) in MiliQ water. Peak identification was performed by spiking with commercially available pamidronate.

Statistical analysis. Statistical analyses were performed using one-way analyses of variance (ANOVA). Post-hoc comparison of means was carried out with Tukey's test for multiple comparisons, when appropriate. In this case all data were shown as the means \pm SEM. In cases of rejected hypothesis of normal distribution or homogeneity of variance nonparametric ANOVA rank Kruskal-Wallis multiple comparisons was used. The data were considered statistically significant at $\mathrm{P}<0.05$. All statistical calculations were performed using 10.0 STATISTICA software (StatSoft, Poland).

\section{Results}

In the first step of the experiment, the elution of pamidronate from probes of BP-enriched bone cement, after 3 and 6 weeks of incubation, was determined by ion-pair HPLC. The ion-pair HPLC analysis was based on a previous publication in which pamidronate was quantitated on Phenomenex Luna C 18 column using $10 \mathrm{mM} \mathrm{n}$-amylamine and a constant $\mathrm{pH}$ of 7.0 and acetonitrile (14\%) (v/v) (16). The content of pamidronate ranged from 0.05 to $1,000 \mu \mathrm{g} / \mathrm{mL}$. In the method, the correlation coefficient was higher than 0.99 , demonstrating a linear correlation between the concentration and the obtained response. The linear regression equation and correlation coefficient values are shown in Table 1.

In the experiment, pamidronate was eluted from the column providing a narrow, sharp peak confirming the presence of pamidronate in the $0.9 \% \mathrm{NaCl}$ solution after 3 and 6 weeks of incubation. The maximum concentration of pamidronate was $1.25 \mathrm{mg} / \mathrm{mL}$ after 6 weeks of incubation (Table 2) and was higher than after 3 weeks of incubation ( $p=0.0072)$.

In the next stage of the study, the results obtained by ion-pair HPLC were confirmed by capillary electrophoresis. Pamidronate was eluted from probes of BP-enriched bone cement after 3 and 6 weeks of incubation. Under the optimised $\mathrm{CE}$ conditions, pamidronate dissolved in a $0.9 \% \mathrm{NaCl}$ solution gave a sharp peak at about $6.8 \mathrm{~min}$ migration time (Figs 1A, 1B).

Table 1

Linear regression calibration and detection limit data for pamidronate eluted from bone cement

\begin{tabular}{cccc}
\hline $\begin{array}{c}\text { Concentration } \\
\text { range } \\
(\mu \mathrm{g} / \mathrm{mL})\end{array}$ & Regression line & $\begin{array}{c}\text { Corelation coefficient } \\
(\mathrm{r})\end{array}$ & $\begin{array}{c}\text { Detection limit } \\
(\mu \mathrm{g} / \mathrm{mL})\end{array}$ \\
\hline $0.05-1000$ & $\mathrm{y}=1.2299 \mathrm{x}-6.266$ & 0.9999 & 0.115 \\
\hline
\end{tabular}


Table 2

Analysis of concentrations of pamidronate in $0.9 \% \mathrm{NaCl}$ solution by ion-pair HPLC

\begin{tabular}{lccc}
\hline Time & $\begin{array}{c}\text { Concentration } \\
(\mathrm{mg} / \mathrm{mL})\end{array}$ & $\begin{array}{c}\text { Found amount } \\
\text { in standard }(\%)\end{array}$ & $\mathrm{N}$ \\
\hline 3 weeks & 0.35 & $98.68 \pm 1.89$ & 5 \\
6 weeks & 1.25 & $97.78 \pm 1.92$ & 5 \\
\hline
\end{tabular}

Table 3

Analysis of concentration of pamidronate in $0.9 \% \mathrm{NaCl}$ solution by $\mathrm{EC}$

\begin{tabular}{ccccc}
\hline $\begin{array}{c}\text { Incubation } \\
\text { time }\end{array}$ & $\begin{array}{c}\text { Migration times } \\
(\mathrm{min})\end{array}$ & Peak areas & $\begin{array}{c}\text { Concentration } \\
(\mathrm{mg} / \mathrm{mL})\end{array}$ & $\mathrm{N}$ \\
\hline 3 weeks & 6.847 & $7,375.0$ & 0.345 & 5 \\
6 weeks & 6.837 & $27,872.5$ & 1.320 & 5 \\
\hline
\end{tabular}

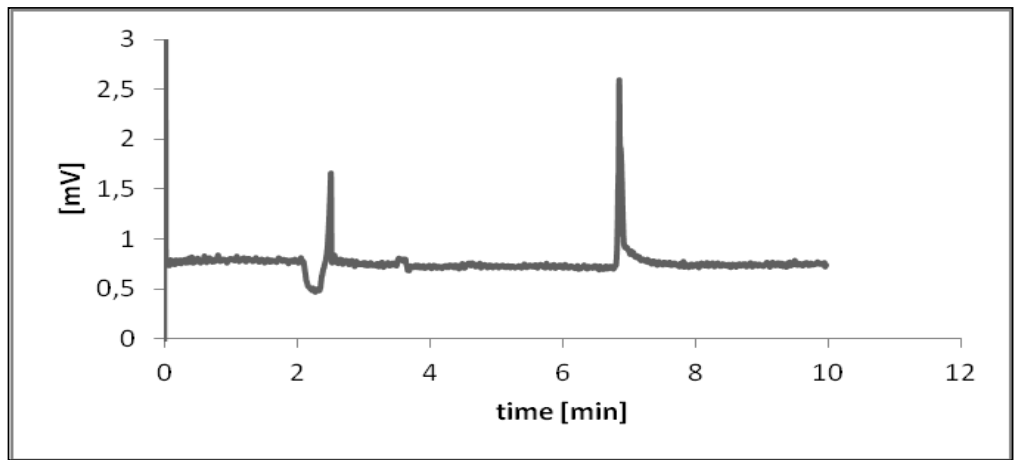

Fig. 1A. Electropherogram of pamidronate in $0.9 \% \mathrm{NaCl}$ solution, after 3 weeks of incubation



Fig. 1B. Electropherogram of pamidronate in $0.9 \% \mathrm{NaCl}$ solution, after 6 weeks of incubation

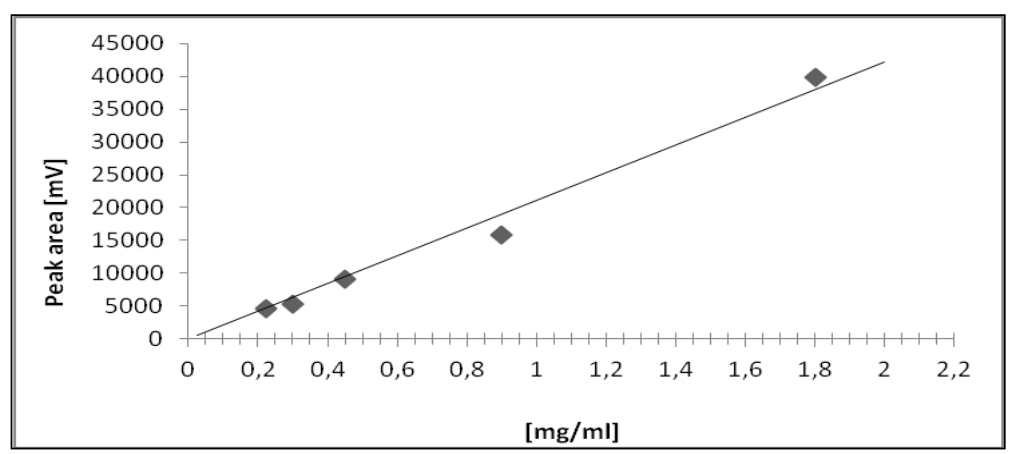

Fig. 2. Concentration of pamidronate standard in $0.9 \% \mathrm{NaCl}$ solution 
For injection precision, measured by integrated peak areas of five replicate injections, the RSD values of the 0.5 and $2.0 \mathrm{mg} / \mathrm{m}$ pamidronate solution were 1.74 and $1.98 \%$, respectively. The detector response was found to be linear $(y=12.783 x+7430)$ and showed $R^{2}$ of 0.9993 for the investigated concentration range 0.1-6.0 $\mathrm{mg} / \mathrm{mL}$ using pamidronate standard solutions (Fig. 2).

The results obtained by capillary electrophoresis were similar to those obtained by ion-pair HPLC. The maximum concentration of pamidronate was $1.32 \mathrm{mg} / \mathrm{mL}$ after 6 weeks of incubation (Table 3 ) and was higher than after 3 weeks of incubation $(p=0.0078)$.

\section{Discussion}

Bisphosphonates play an important role as antiresorptive drugs for the prevention and treatment of osteoporosis. They increase bone mass and produce a reduction in fracture rates to approximately half of control rates in the spine, hip, and other sites in postmenopausal women. In addition to the inhibition of osteoclasts, the ability of bisphosphonates to reduce the activation frequency and birth rates of new bone remodelling units, and possibly to enhance osteon mineralisation, may also contribute to the reduction in fractures $(28,29)$. The compounds have been registered for various clinical applications. They are usually given parenterally, or orally. However, there are some reports concerning side effects, especially during oral and longterm treatment $(18,21,26,33)$.

Arthroplasty patients with an orthopaedic implant device are at high risk for osteopenia or osteoporosis. Total joint replacement can be complicated by subsequent aseptic loosening the implant. The pathogenesis of implant-associated osteolysis includes inflammatory and osteolytic processes (1, 11, 26). Recent studies have indicated that the use of BPs' is connected with the improvement of the implant survival after total arthroplasty of the knee or hip. It may be very helpful in prevention of periprosthetic bone loss and failure of joint prosthesis $(10,26)$.

A modular prosthesis, which is based on many of the technical advances found in human prostheses, is now available for use in veterinary medicine. Currently, total hip and elbow replacements are commercially available options viable for use in dogs. Aseptic loosening that develops osteoarthritis is likely to be developed in the near future. The bisphosphonate drugs are also used in veterinary medicine for the suppression of bone remodelling and tumour osteolysis as a palliative treatment of animals with osteosarcoma (32).

The details of bisphosphonate leaking from the cured bone cement into a biosimulating solution are described by Lewis et al. (16). BPs are strongly polar and ionic and are non volatile (31). Nowadays, bisphosphonates are used in lower doses, which increases the demands for sensitive analyses, therefore, it can be only detected by chromatographic methods (6). For the development of analytical separation methods, several strategies have been applied, mainly IEC (ion- exchange chromatography) and reversed-phase liquid chromatography (RPLC), often in combination with an ion-pairing agent $(5,15)$. In 2006, Jia et al. (14) described the development, optimisation, and validation of ion-pair HPLC with UV detection procedure for the analysis of risedronate in rat plasma. They reported that this method is simple and the most economic of the extraction procedures. They proposed that ion-pair HPLC method is a robust and reliable method for determination of risedronate in plasma and can be used to detect low concentrations of other bisphosphonates usually found in such samples (14). In this study, ionpair HPLC method, which was described in an earlier report (19), had detection limit of pamidronate about $10^{-7}-10^{-8} \mathrm{~g} / \mathrm{mL}$, i.e. 10 to 100 times lower than method of Xie et al. (35) where the ELSD detector was used. The precision of the data and the agreement between the label claim and the amounts found were very high.

Capillary electrophoresis was the next method used in the study. Many authors claim that this method is very useful $(12,30,37)$. Perjesi et al. (24) reported that $\mathrm{CE}$ is a simple and easy to perform method for quantification of clodronate in liposomal formulation. This reproducible method may be routinely applied as quality control during the preparation of liposomal formulation of bisphosphonate. A capillary zone electrophoretic (CZE) method has been developed for the determination of impurities (phosphyte and phosphate) in technical-grade ibandronate, which is a potent nitrogen-containing bisphosphonate $(3,27)$. The potential of multidimensional capillary electrophoretic methodological approaches, which eliminate sample preparation have been evaluated with regard to the analysis of bisphosphonates in aqueous and urinary matrices. Capillary isotachophoresis (cITP) was employed as a pre-separation and on-line sample concentration step prior to analytical determination using either cITP or CZE with conductivity detection (3).

The results obtained by ion-pair HPLC and CE methods showed that pamidronate is eluted from the BPenriched bone cement after both 3 and 6 weeks of incubation in $0.9 \% \mathrm{NaCl}$ solution. Wherein, after 6 weeks of incubation, the amount of pamidronate released from a sample was more than 4-fold higher than after 3 weeks of incubation. The release of pamidronate with BP-enriched bone cement also explains enhancement of the microstructure of bones in rats treated with BP-enriched bone cement in our former experiments (20). All these factors improved bone turnover toward reducing bone resorption and significantly improved the bone quality. Such methods of administering a BP-enriched bone cement, e.g., pamidronate, to a patient's periprosthetic bone area may prevent bone resorprtion and aseptic loosening at the site of the medical implant devices. The slowing of the rate of bone resorption, is hypothesised to be associated with an improvement in the local bone turnover in the periprosthetic bone, which may provide a greater integrity to the overall bone and prosthesis structure. It is also suggested that BP-enriched bone cement can be successfully used in animals for filling bone defects that 
arise as a result of a variety of diseases or injuries and in joint replacements as well. Thus, it is thought that the use of BP-enriched bone cement may be very beneficial in veterinary medicine. The results obtained with BPenriched bone cement in rat models encouraged to prepare further clinical in vivo studies.

Acknowledgments: This paper was prepared with the support and help of Ashwani Srivastava MD student, Ca. USA. The authors wish to express their gratitude to him. He offered an invaluable assistance and support during editing of this article. It has greatly improved the clarity and sense of the manuscript.

\section{References}

1. Abu-Amer Y., Darwech I.: Aseptic loosening of total joint replacements: mechanisms underlying osteolysis and potential therapies. Arthritis Res Ther 2007, 9 (Suppl 1), S6.

2. Åstrand J., Aspenberg P.: Reduction of instabilityinduced bone resorption using bisphosphonates. High doses are needed in rats. Acta Orthop Scand 2002, 73, 2430.

3. Bexheti D., Anderson E.I., Hutt A.J., Brown M.A.: Evaluation of multidimensional capillary electrophoretic methodologies for determination of amino bisphosphonate pharmaceuticals. J Chromatograph A 2006, 1130, 137-14.

4. Bock O., Börst H., Beller G., Armbrecht G., Degner C., Martus P., Roth H.J., Felsenberg D.: Impact of oral ibandronate $150 \mathrm{mg}$ once monthly on bone structure and density in post-menopausal osteoporosis or osteopenia derived from in vivo $\mu \mathrm{CT}$. Bone 2012, 50, 317-24.

5. Daley-Yates P., Gifford L., Hoggarth C.: Assay of 1hydroxy-3-aminopropylidene-1,1-bisphosphonate and related bisphosphonates in human urine and plasma by high-performance ion chromatography. J Chromatogr B: Biomed Sci Appl 1989, 490, 329-338.

6. Fleisch H.: Bisphosphonates: mechanisms of action. Endcrinol Rev 1998, 19, 80-102.

7. Frith J.C., Monkkonen J., Blackburn G.M., Russell R.G., Rogers M.J.: Clodronate and liposome-encapsulated clodronate are metabolized to a toxic ATP analog, adenosine 5 '-( $\beta, \gamma$-dichloromethylene) triphosphate, by mammalian cells in vitro. J Bone Miner Res 1997, 12, 1358-1367.

8. Gao Y., Zou S., Liu X., Bao Ch., Jing H.: The effect of surface immobilized bisphosphonates on the fixation of hydroxyapatite-coated titanium implants in ovariectomized rats. Biomaterials 2009, 30, 1790-1796.

9. Geoffroy V., Paschalis E.P., Libouban H., Blouin S., Ostertag A., Chappard D., Cros M., Phipps R., de Vernejoul M.C.: Effects of risedronate in Runx2 overexpressing mice, an animal model for evaluation of treatment effects on bone quality and fractures. Calcif Tissue Int 2011, 88, 464-475.

10. Goldring S.R., Gravallese E.M.: Bisphosphonates: environmental protection for the joint? Arthritis Rheum 2004, 50, 2044-2047.

11. Goodship A.E., Blunn G.W., Green J., Coathup M.J.: Prevention of strain-related osteopenia in aseptic loosening of hip prostheses using perioperative bisphosphonate. J Orthop Res 2008, 26, 693-703.
12. Huikko K., Kostiainen R.: Development and validation of a capillary zone electrophoresis method for the determination of bisphosphonate and phosphonate impurities in clodronate. J Chromatogr A 2000, 893, 411420.

13. Jakobsen T., Bass J., Bechtold J.E., Elmengaard B., Soballe K.: Soaking morselized allograft bone in bisphosphonate can impair implant fixation. Clin Orthop 2007, 463, 195-201.

14. Jia H.J., Li W., Zhao K.: Determination of risedronate in rat plasma samples by ion-pair high-performance liquid chromatography with UV detector. Anal Chim Acta 2006, 562, 171-175.

15. Kwong E., Chiu A.M.Y., McClintock S.A., Cotton M.L.: HPLC analysis of an amino bisphosphonate in pharmaceutical formulations using post-column derivatization and fluorescence detection. J Chromatogr Sci 1990, 28, 563-566.

16. Lewis G., Janna S.: Aldendronate in bone cement. Clin Orthop Rel Res 2006, 445, 233-238.

17. Makkonen N., Hirvonen M-R., Teräväinen T., Savolainen K., Mönkönen J.: Different effects of three bisphosphonates on nitric oxide production by Raw 264 macrophage-like cells in vitro. J Pharm Exp Ther 1996, 277, 1097-1102.

18. Marx R.E.: Pamidronate (Aredia) and zoledronate (Zometa) induced a vascular necrosis of the jaw: a growing epidemic. J Oral Maxillofac Surg 2003, 61, $1115-1117$

19. Matuszewski Ł., Matuszewska A., Mazurkiewicz T., Rogalski J., Cho N.S., Ohga S.: Determination of bisphosphonates by ion-pair HPLC. J Fac Agr Kyushu Univ 2011, 56, 213-216.

20. Matuszewski Ł, Turżańska K, Matuszewska A, Jabłoński M, Polkowska I, Mazurkiewicz T.: Effect of implanted bisphosphonate-enriched cement on the trabecular microarchitecture of bone in a rat model using microcomputed tomography. International Orthopaedics. $\mathrm{http} / / /$ www.springer.com/alert/urltracking.do?id=Lfb8 d2bMbe6f65Saad8ca1. Accessed 24 February 2013.

21. Mazurkiewicz T., Matuszewski Ł., Matuszewska A., Jaszek M.: Implanted bisphosphonates in bone cement affect bone markers in rat serum. International Orthopaedics. http://link.springer.com/article/10.1007/ s00264-013-1816-6. Accessed 26 January 2013.

22. Migliorati C.A.: Bisphosphonates and oral cavity bone necrosis. J Clin Oncol 2003, 21, 4253-4254.

23. Morris C.D., Einhorn T.A.: Bisphosphonates in orthopedic surgery. J. Bone Joint Surg 2005, 87, 16091618.

24. Perjesi P., Kim T., Zharikova A.D., Li X., Ramesh T., Ramasubbu J., Prokai L.: Determination of clodronate content in liposomal formulation by capillary zone electrophoresis. J Pharma Biomed Anal 2003, 31, 929935.

25. Peter B., Gauthier O., Laib S., Bujoli B., Guicheux J., Janvier P.: Local delivery of bisphosphonate from coated orthopedic implants increases implant mechanical stability in osteoporotic rats. J Biomed Mater Res A 2006, 76, 133-143.

26. Prieto-Alhambra D., Javaid M., Judge A., Murray D., Carr A., Cooper C., Arden N.: Association between bisphosphonate use and implant survival after primary total arthroplasty of the knee or hip: population based retrospective cohort study. BMJ 2011. http://dx.doi.org/10.1136/bmj.d722.

27. Rodriquez J.A.B., Desimone M.F., Iglesias S.L., Giorgieri S.A., Diaz L.E.: Validation of a capillary electrophoresis 
method for the analysis of ibandronate related impurities. J Pharm Biomed Anal 2007, 44, 305-308.

28. Russell R.G.G., Rogers M.J.: Bisphosphonates: from the laboratory to the clinic and back again. Bone 1999, 25, 97-106.

29. Schindeler A., Birke O., Yu N.Y., Morse A., Ruys A., Baldock P.A., Little D.G.: Distal tibial fracture repair in a neurofibromatosis type 1-deficient mouse treated with recombinant bone morphogenetic protein and a bisphosphonate. J Bone Joint Surg Br 2011, 93, 11341139.

30. Sirén H., Määttänen A., Riekkola M.L.: Determination of small anions by capillary electrophoresis using indirect UV detection with sulphonated nitrosonaphtol dyes. J Chromatogr A 1997, 767, 293-301.

31. Sparidans R.W., Hartigh J.: Chromatographic analysis of bisphosphonates. Pharm World Sci 1999, 21, 1-10.

32. Tomlin J.L., Sturgeon C., Pead M.J., Muir P.: Use of bisphosphonate drug aldendronate for palliative management of osteosarcoma in two dogs. Vet Rec 2000, 147, 129-132.
33. Wilkinson J.M., Little D.G.: Bisphosphonates in orthopedic applications. Bone 2011, 49, 95-102.

34. Viereck V., Emons G., Lauck V., Frosch K.H., Blaschke S., Grundker C., Hofbauer L.: Bisphosphonates pamidronate and zoledronic acid stimulate osteoprotegerin production by primary human osteoblasts. Biochem Biophys Res Commun 2002, 291, 680-668.

35. Xie Z.X., Jiang Y., Zhang D.Q.: Simple analysis of four bisphosphonates simultaneously by reverse phase liquid chromatography using $\mathrm{n}$-amylamine as volatile ionpairing agent. J Chromatogr 2006, 1104, 173-178.

36. Xuenong Z., Qingyun X., Haishengen L., Bunger M., Lind M., Bunger C.: Effect of alendronate on bone in growth into porous tantalum and carbon fiber interbody devices. Acta Orthop Scand 2003, 74, 596-603.

37. Zacharis C.K., Tzanavaras P.D.: Determination of bisphosphonate active pharmaceutical ingredients in pharmaceuticals and biological material: A review of analytical methods. J Pharma Biomed Anal 2008, 48, 483-496. 